\title{
Design and Construction of Spud Housing for Floating Dock
}

\author{
Hasanudin Hasanudin ${ }^{1, *}$, and Ardi Nugroho Yulianto ${ }^{1}$ \\ ${ }^{1}$ Department of Naval Architecture, Institut Teknologi Sepuluh Nopember, 60111, Surabaya, \\ Indonesia
}

\begin{abstract}
A floating dock is a type of pontoon for dry docking ships, possessing floodable buoyancy chambers. The Floating docks have more advantages than the other type of ship docking for maintenance. The purpose of the research study is to design and calculate of spud housing construction for floating dock. The spud housing is used to keep of floating dock in the safe condition. Mild steel material is used to construction of spud housing with yield point $235 \times 10^{6} \mathrm{~N} / \mathrm{m}^{2}$. Design calculations were done by finite element analysis (FEA). The minimum stress is 1042.36 $\mathrm{N} / \mathrm{m}^{2}$ and minimum deflection is $0.447 \mathrm{~mm}$. The maximum stress is 0.142 $x 10^{9} \mathrm{~N} / \mathrm{m}^{2}$ and maximum deflection is $4.019 \mathrm{~mm}$. The maximum stress is not more than yield point of material.
\end{abstract}

\section{Introduction}

\subsection{Floating dock}

The floating dock is also modern in concept when compared with the history connected with graving docks and marine railways. The earliest known use of the floating dock principle was about 1700 when a British Royal Navy Captain, lacking other means of docking facilities, bought an old hulk, gutted it and fitted it with a watertight stern gate, docked his ship therein and pumped the water from the hulk [1].

A floating dock is a type of pontoon for dry docking ships, possessing floodable buoyancy chambers and a "U"-shaped cross-section that show on figure 1. The Floating docks have more valuable than the other type of ship docking. The walls are used to give the dry dock stability when the floor or deck is below the surface of the water. When valves are opened, the chambers fill with water, causing the dry dock to float lower in the water. The deck becomes submerged and this allows a ship to be moved into position inside. When the water is pumped out of the chambers, the dry dock rises and the ship is lifted out of the water on the rising deck, allowing work to proceed on the ship's hull. A typical floating dry dock involves multiple rectangular sections. These sections can be combined to handle ships of various lengths, and the sections themselves can come in different dimensions. Each section contains its own equipment for emptying the ballast and to

*Corresponding author: hasanudin@na.its.ac.id, ardi.nugroho@na.its.ac.id 
provide the required services, and the addition of a bow section can facilitate the towing of the dry dock once assembled. For smaller boats, one-piece floating dry docks can be constructed, potentially coming with their own bow and steering mechanism [1].

The Floating docks have more advantages than the other type for ship maintenance. They offer large construction advantages and thereby contribute greatly to faster mobilization. They can be constructed in areas where materials and labor are available and then moved to the working site which may be considerably removed from the site of construction. Furthermore, the time required for construction of floating dock is less than that for a comparable size graving dock. In addition, our present pattern for all large docks is to construct them in sections. This method of building lends itself to the use of building contractors at different sites working upon the same dock simultaneously and thereby further reducing considerably the time of construction [1].

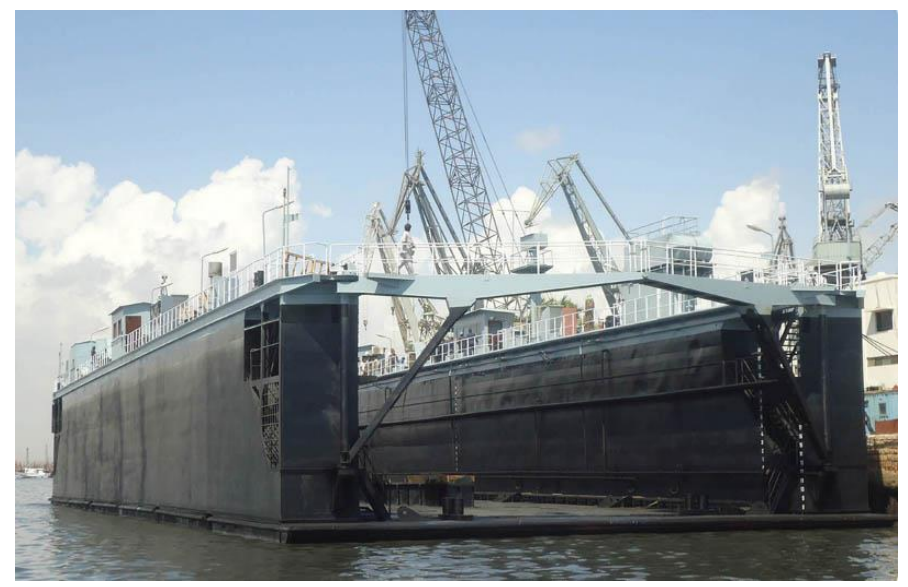

Fig. 1. Floating Dock.

\subsection{Spud housing}

Floating docks are moored in any one of several ways. In general, docks used in a yard are moored to a pier by means of spuds. This method of mooring consists essentially of at least 3 jaws connected to a pier or to dolphins. Attached to the dock in a vertical position and riding up and down in the jaws as the dock is flooded and pumped, are three long mooring spuds in the general form of H-beams. These spuds extend far enough down the side of the dock so that they will not come out of the jaws when the dock is at light draft and they extend far enough up the side of the deck so that the jaws remain engaged at maximum submerged. The centre spud resists forces parallel to the longitudinal centreline of the dock while the two end spuds resist only forces in a transverse direction. Use of the spud mooring is limited to docks where the required depth of water can be obtained next to a pier or dolphin. Figure 2 shows spud housing of floating dock [1]. 


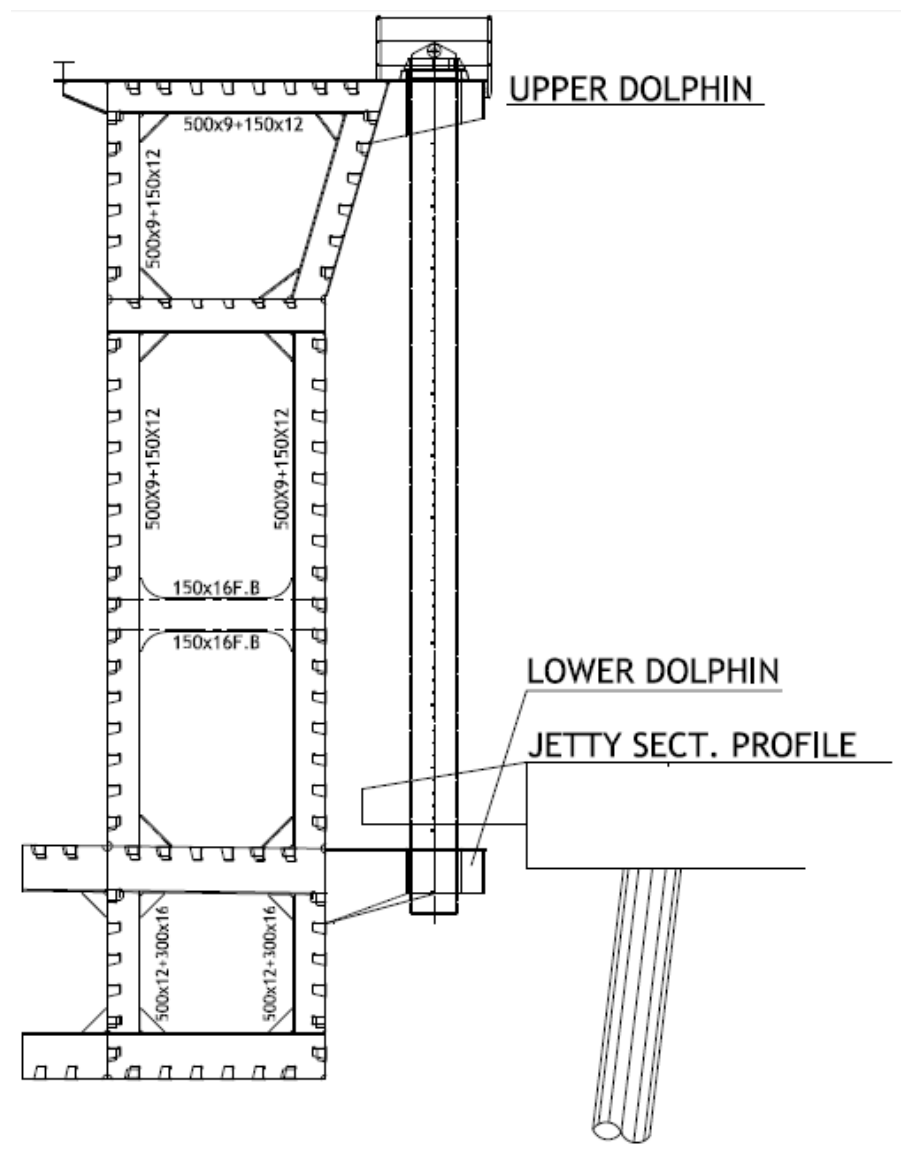

Fig. 2. Spud housing of floating dock.

\subsection{Finite Element Analysis}

Finite element analysis (FEA) is a computational technique used to obtain approximate solutions of boundary value problems in engineering. A boundary value problem is important for this analysis. It is a mathematical problem in which one or more dependent variables must satisfy a differential equation everywhere within a known domain of independent variables and satisfy specific conditions on the boundary of the domain. It is also sometimes called field problems. Figure 3 shows the general techniques and terminology of finite element analysis. Figure 3 depicts a volume of some material or materials having known physical properties. The volume represents the domain of a boundary value problem to be solved. For example, at this point, it assumes a twodimensional case with a single field variable $\mathrm{P}(\mathrm{x}, \mathrm{y})$ such that a known governing equation is satisfied exactly at every such point [2]. 


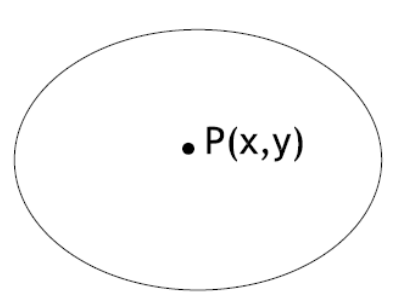

(a)

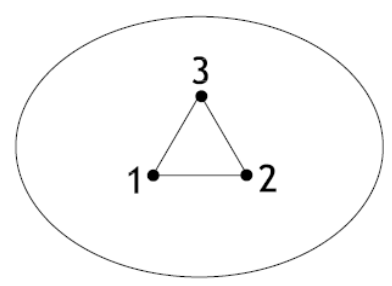

(b)

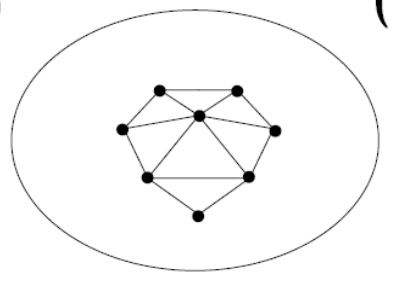

(c)

Fig. 3. (a) A general two-dimensional domain of field Variable $\mathrm{P}(\mathrm{x}, \mathrm{y})$. (b) A three-node finite element defined in the domain. (c) Additional element.

\section{Method}

\subsection{Model preparation}

Preparation of the model is done with the help of software modeling with AutoCAD. Construction of spud housing will be placed in the side of floating dock as seen in figure 4. There are some modification from original design of floating dock to support spud housing structure that will be installed on the deck of floating dock. The structure model is shown in Figure 5 .

\section{UPPER DECK PLAN}

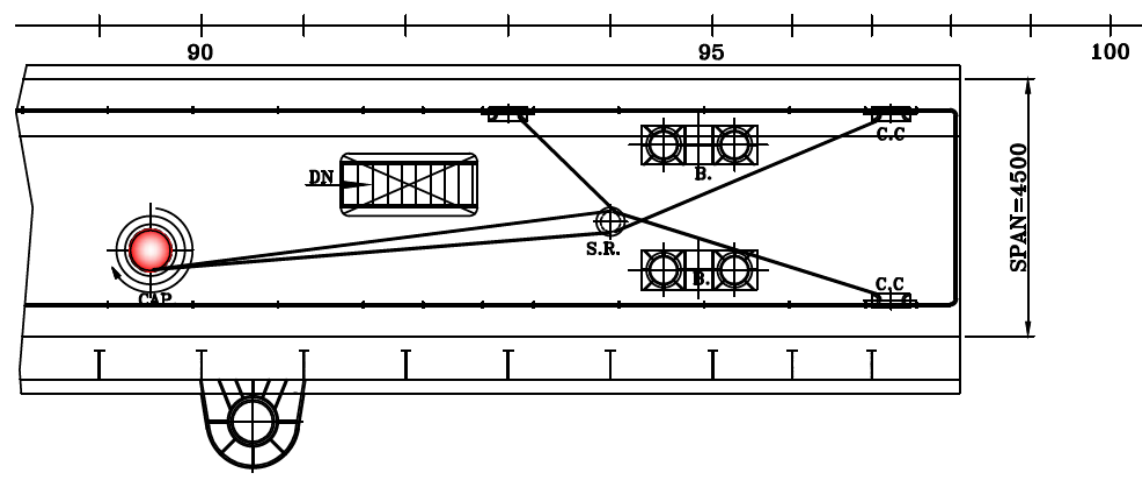

INSIDE

Fig. 4. Deck arrangement of floating dock for spud housing. 


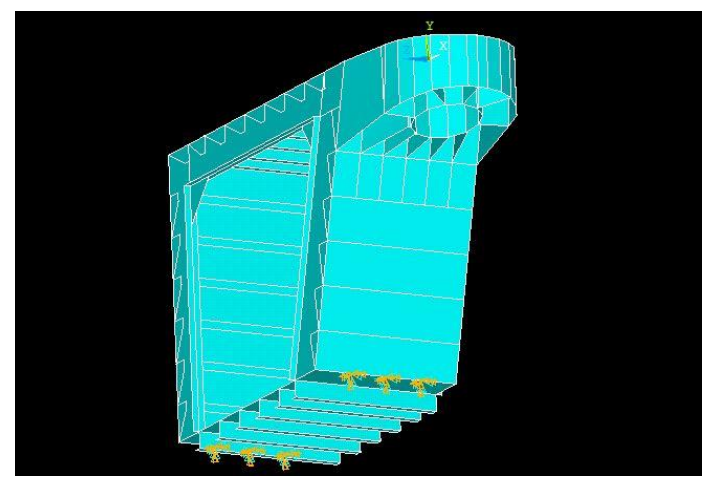

Fig. 5. Construction of spud housing.

\subsection{Simulation}

Finite element methods are numerical methods for approximating the solutions of mathematical problems that are usually formulated so as to precisely state an idea of some aspect of physical reality [3,4]. A finite element method is characterized by a variational formulation, a discretization strategy, one or more solution algorithms and post-processing procedures. Examples of variational formulation are the Galerkin method, the discontinuous Galerkin method, mixed methods, etc. There are various numerical solution algorithms that can be classified into two broad categories; direct and iterative solvers. These algorithms are designed to exploit the sparsity of matrices that depend on the choices of variational formulation and discretization strategy. There are some very efficient postprocessors that provide for the realization of super-convergence. There are some step of this method. It has been divided by Pre-processor, Processor/Solver, Post-processor. Preprocessor phase is the process that prepare for dimension of model for $3 \mathrm{D}$ model that use to calculation in the solver phase [5]. Processor/Phase is the process that calculate based on model preparation, boundary, load and the other factor. Post-processing procedures are designed for the extraction of the data of interest from a finite element solution. In order to meet the requirements of solution verification, postprocessors need to provide for a posteriori error estimation in terms of the quantities of interest. When the errors of approximation are larger than what is considered acceptable then the discretization has to be changed either by an automated adaptive process or by action of the analyst. Postprocessor shown graph, curve, contour [6]. For Finite Element Analysis, element model should follow as the following requirements:

a. The global Finite element model should be made of shell elements for the hull plating and frame in the hull.

b. Stiffeners may be modelled as a beam element provided the effective plate flange width comply with rules.

\subsection{Material properties}

Below the material properties and load of the hull structure which applied in the strength analysis:
a. Modulus of Elasticity $=210 \times 109 \quad \mathrm{~N} / \mathrm{m}^{2}$
b. Poisson's Ratio $\quad=0.32$
c. Steel Density $\quad=7850$
d. Material Grade = A (Mild Steel) 

e. Yield Point
$=235 \times 10^{6} \quad \mathrm{~N} / \mathrm{m}^{2}$
f. Elongation Min
$=22 \%$
g. Pressure load $(20 \mathrm{~T})$
$=3001192$
$\mathrm{N} / \mathrm{m}^{2}$

\section{Analysis of spud housing structure}

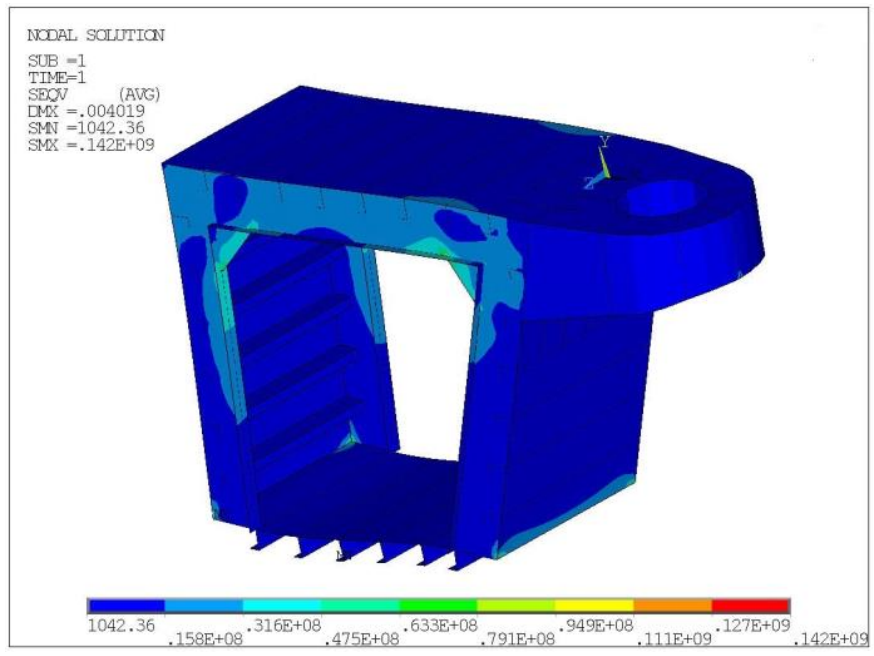

Fig. 6. Stress of spud housing structure

Figure 6 shows stress of spud housing structure from finite element calculation. It can be seen the result of finite element analysis in the post-processing for contour of von mises stress and deflection. In this simulation, it gives for load 20 ton based on self-weight of spud housing structure and additional load from environment factor. For this model, it uses material grade A with yield point $235 \times 10^{6} \mathrm{~N} / \mathrm{m}^{2}$. It can be seen that the value of minimum stress $1042.36 \mathrm{~N} / \mathrm{m}^{2}$, the value of maximum stress $0.142 \times 10^{9} \mathrm{~N} / \mathrm{m}^{2}$, the value of minimum deflection $0.447 \mathrm{~mm}$, the value of maximum deflection $4.019 \mathrm{~mm}$.

\section{Conclusion}

In this paper, finite element method is used to get the maximum stress of spud housing construction. The maximum stress of spud housing construction is not more than yield point of mild steel (grade A). It has minimum stress $1042.36 \mathrm{~N} / \mathrm{m}^{2}$, maximum stress $0.142 \mathrm{x}$ $10^{9} \mathrm{~N} / \mathrm{m}^{2}$, the minimum deflection $0.447 \mathrm{~mm}$ and the maximum deflection $4.019 \mathrm{~mm}$.

\section{References}

1. V. E. Cook, General discussion of floating drydocks 1, 289-306(1957)

2. D. V. Hutton, Fundamentals of finite element analysis, 2 (2004)

3. K. J. Bathe, Numerical methods in finite element analysis, 11 (1976)

4. J. Chaskalovic, Finite elements methods for engineering sciences, 2 (2000)

5. O. C. Zienkiewicz, R. L. Taylor, The finite element method, 1 (2000)

6. A. N. Yulianto, D. Atmono, M. S. Arif, Design and construction of crawler crane seating for floating dock, 3 (2015) 